\title{
Maternal perceptions of their child's weight status: the GENESIS study
}

\author{
Yannis Manios*, Katerina Kondaki, Georgia Kourlaba, Emilia Vasilopoulou and \\ Evangelia Grammatikaki \\ Department of Nutrition and Dietetics, Harokopio University of Athens, 70 El. Venizelou Avenue, \\ 17671 Kallithea, Athens, Greece
}

Submitted 28 February 2008: Accepted 4 November 2008: First published online 24 December 2008

\begin{abstract}
Objective: The objective of the present work was to quantify mothers' misclassification of pre-school children's weight status and to determine factors associated with the maternal misperception.

Design: A representative sample of 2287 children aged 2-5 years was examined (GENESIS study). Mothers' perceptions of their child's weight status and the children's and mothers' anthropometric and other characteristics (sociodemographic and lifestyle) were recorded.

Results: Almost 38\% of mothers underestimated their child's weight status. The frequency of underestimation was much higher among 'at risk of being overweight' and 'overweight' children ( $88.3 \%$ and $54.5 \%$, respectively) compared with 'underweight/ normal-weight' children $(18 \cdot 0 \%, P<0 \cdot 001)$. Multiple logistic regression modelling revealed that the likelihood of mothers' underestimation of their child's weight status was significantly higher in boys, in children engaging in physical activity for less than $3 \mathrm{~h} /$ week and in children whose mothers had low education status, compared with their counterparts. Moreover, the higher the BMI-for-age Z-score, the greater the odds that the mother would underestimate her child's weight status.

Conclusions: The current study demonstrated that more than one-third of mothers misclassify their children's weight status as being lower than the actual. Given that mother's weight perception might be an important determinant of child's body weight development, clinicians and health professionals should help mothers correctly classify their children's weight status, which could potentially help in the early prevention of overweight and obesity.
\end{abstract}

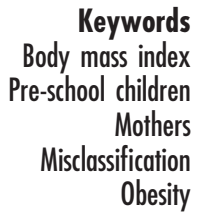

Overweight and obesity in children has increased dramatically over the past two decades, becoming a major public health problem in most industrialized countries as well as in countries in economic transition ${ }^{(1-5)}$. It has been shown that overweight children are more likely to become ${\text { obese } \text { adults }^{(6,7)} \text {. Moreover, numerous social }}^{(8)}$, physical and emotional consequences of obesity ${ }^{(9,10)}$, including type 2 diabetes $^{(11)}$, hypertension and increased cardiovascular risk $^{(12,13)}$, obstructive sleep apnoea ${ }^{(14)}$ and poor quality of life ${ }^{(15)}$, may be evident even in very young children and persist into adulthood. The identification of children who are overweight or at risk of becoming overweight is therefore of critical importance; if excessive weight problems are recognized early in life, prevention and treatment strategies are likely to be more successful ${ }^{(16)}$.

It is a well-known fact that parents influence the eating ${ }^{(17,18)}$ and physical activity patterns ${ }^{(19,20)}$ of pre-school and school-aged children. In this context, parental involvement is important for the successful outcome of childhood obesity preventive actions ${ }^{(21-23)}$. However, to achieve active parental engagement in such actions, parents should be able to recognize their children's excessive body weight and be aware of its potential health consequences ${ }^{(23)}$. If parents cannot recognize that their children are heavy for their age or do not realize the health risks associated with overweight, then childhood obesity prevention or treatment programmes are unlikely to be successful ${ }^{(16)}$.

Although limited in number, the studies investigating mothers' or parents' perceptions of children's weight status have demonstrated that a considerable number of mothers/parents cannot estimate their child's weight correctly ${ }^{(16,23-28)}$. Some of these studies have focused on factors influencing the maternal/parental misperception $^{(16,23,29)}$ and their findings suggest that parental perceptions are influenced by children's characteristics such as age, sex and measured weight status ${ }^{(16,29)}$, as well as mothers' educational level ${ }^{(23)}$. Other studies have only explored parents' perceptions of their child's appearance ${ }^{(25,28)}$, while the study of Kroke et al. ${ }^{(24)}$ showed 
that mothers' perceptions of their child's weight status are associated with the development of body weight in later life.

The majority of the aforementioned studies were conducted in children older than 2 years of age and included a wide range of ages. Only one study has considered the critical early life period $^{(24)}$. Moreover, no previous study has investigated mothers' misclassification rate of their child's weight status among the Greek population, although the prevalence of childhood obesity in Greece is among the highest worldwide ${ }^{(3)}$.

Therefore, the present paper aims to evaluate the maternal misclassification rate (especially underestimation) of child weight status in a sample of Greek children aged between 2 and 5 years. Moreover, the factors associated with the maternal misperception rate are examined. Mothers' and children's anthropometric and sociodemographic characteristics, as well as children's lifestyle characteristics (i.e. child's physical activity), were used as the investigating factors.

\section{Methods}

\section{Sampling}

The design and rationale of the Growth, Exercise and Nutrition Epidemiological Study in preSchoolers (GENESIS study) have been published previously ${ }^{(30)}$. In brief, between April 2003 and July 2004, 2518 children aged 1 to 5 years were recruited to the study. This sample was enrolled from a representative sample of randomly selected public and private nurseries as well as day-care centres within municipalities in five counties. All nurseries invited to participate responded positively. The sampling of the nurseries was random, multistage and stratified by the total population of children, according to data provided by the National Statistical Service of Greece (Census 1999). Each parent having a child in these nurseries received an extended letter explaining the aims of the current study and a consent form. Those parents agreeing to participate in the study had to sign the consent form and provide their contact details. From the total number of positive responses (response rate $75 \%$ ), complete data became available for 2374 children (2287 were aged 2 years or older). Parents' perceptions of their child's weight status were recorded for 1859 children. Among those, we excluded records in which the interview respondent was not the mother of the participating child ( $n$ 100). No significant differences were observed when comparing the distribution of parental age and educational level of the participating cohort with that of the overall population (as provided by the National Statistical Service of Greece (Census 1999)). Approval to conduct the study was granted by the Ethical Committee of Harokopio University of Athens and by all municipalities invited to participate in the study.

\section{Antbropometric measurements}

Body weight was recorded to the nearest $10 \mathrm{~g}$, recumbent length to the nearest $0 \cdot 1 \mathrm{~cm}$ and standing height to the nearest $0 \cdot 1 \mathrm{~cm}$. Details about the procedures used in performing the aforementioned measurements are presented elsewhere ${ }^{(30)}$. BMI was calculated as the ratio of weight to the square of height $\left(\mathrm{kg} / \mathrm{m}^{2}\right)$. The Nutstat module of the EpiInfo Database and Statistics Software for Public Health Professionals (Centers for Disease Control and Prevention (CDC), Atlanta, GA, USA) was used to determine children's age- and sex-specific percentiles for weight, length and BMI. The CDC age- and sex-specific growth charts and relative cut-off points were used for the definition of overweight ${ }^{(31)}$. Children older than 24 months were classified as 'at risk of overweight' ( $\geq 85$ th and $<95$ th percentile) and 'overweight' ( $\geq 95$ th percentile) using the BMI-for-age growth chart. The remaining children were classified as 'normal weight' (those with normal weight or underweight). Moreover, in univariate and multivariate analyses, BMI-for-age Z-score was used as an indicator of obesity because it has been proposed that it is optimal for assessing adiposity on a single occasion $^{(32)}$. Finally, mothers' BMI was calculated from self-reported height and weight. Mothers' weight category was assigned according to the categorical BMI definitions of the National Center for Health Statistics as follows ${ }^{(33)}$ : 'normal weight' $\left(18.5 \leq \mathrm{BMI}<25 \mathrm{~kg} / \mathrm{m}^{2}\right)$, 'overweight' $\left(25 \leq \mathrm{BMI}<30 \mathrm{~kg} / \mathrm{m}^{2}\right)$ and 'obese' $\left(\mathrm{BMI} \geq 30 \mathrm{~kg} / \mathrm{m}^{2}\right)$.

\section{Data on mothers and mothers' perceptions of children's weight}

A structured interview was conducted in order to collect additional information regarding the mother's educational level, weight status and age.

To assess mothers' perceptions of their child's weight status, mothers were asked to complete the statement 'I feel my child's weight is...' by choosing one of the following five responses: 'much higher than normal', 'higher than normal', 'normal', 'lower than normal' or 'much lower than normal'. Underestimation errors occurred when children actually being 'at risk of overweight' or 'overweight' were perceived by their mothers as having 'normal,' 'lower than normal' or 'much lower than normal' body weight. Furthermore, underestimation errors occurred when children actually being 'normal weight' were perceived by their mothers as having 'lower than normal' or 'much lower than normal' body weight. Overestimation errors occurred when children actually being 'underweight' or 'normal' were perceived by their mothers as having 'higher than normal' or 'much higher than normal' body weight.

\section{Physical activity assessment}

Information on children's physical activity was obtained from parents during scheduled interviews at the nurseries using a valid, structured questionnaire ${ }^{(3)}$. Parents were asked to provide information on their child's participation 
in outdoor organized or non-organized physical activities while a research team member was recording this information on a proxy questionnaire. Emphasis was placed on light to vigorous physical activity (LVPA) with intensity higher than 4 MET (metabolic equivalents). More information on the type of activities comprising LVPA is presented elsewhere ${ }^{(3)}$. Pre-school children were divided into those having LVPA $\geq 3 \mathrm{~h} /$ week and those having LVPA $<3 \mathrm{~h} /$ week

\section{Statistical analysis}

Continuous variables are presented as means and standard deviations and categorical variables are summarized as relative (\%) frequencies. Associations between categorical variables were tested by the use of contingency tables and the calculation of $\chi^{2}$ tests without the correction of continuity. Associations between continuous and categorical variables were evaluated using Student's $t$ test. Frequency analyses were conducted to determine the percentages of mothers considering their child to have 'much lower than normal', 'lower than normal', 'normal', 'higher than normal' and 'much higher than normal' weight, as well as the mothers' misclassification rate regarding their child's weight status. A $\chi^{2}$ test for trend across ordered groups (i.e. increasing child's age and mother's education status) was performed for identifying any trend in maternal misclassification rate.

Univariate logistic regression analyses were conducted in order to test the crude effect of several factors on the probability of mothers' underestimation regarding their child's weight. Child's sex, age, physical activity status, BMI-for-age Z-score, mother's BMI status, mother's education status and mother's age were used as the possible factors (independent variables). Furthermore, multiple logistic regression analysis was used to identify which of the aforementioned factors was independently associated with maternal misclassification of child weight status. From all of these analyses, odds ratios with 95\% confidence intervals were extracted. A probability value of $5 \%$ was considered as statistically significant. All statistical calculations were performed with the SPSS statistical software package version $14 \cdot 0$ (SPSS Inc., Chicago, IL, USA).

\section{Results}

\section{Characteristics of the child participants and their motbers}

Children's and mothers' characteristics are reported by children's measured weight status in Table 1 . The prevalence of 'at risk of overweight' and 'overweight' in the cohort was found to be $18.97 \%$ and $17 \cdot 24 \%$, respectively. No differences were found between genders regarding the prevalence of 'at risk of overweight' and 'overweight'. More information on the anthropometric characteristics of the cohort has been presented in detail previously ${ }^{(3)}$. The birth weight for gestational age was appropriate for the majority of children (>80\%). Regarding mothers'

Table 1 Children's and mothers' characteristics by child's measured weight status: the GENESIS study

\begin{tabular}{|c|c|c|c|c|c|c|c|}
\hline & \multicolumn{2}{|c|}{ Underweight/normal weight (\%) } & \multicolumn{2}{|c|}{ At risk for overweight (\%) } & \multicolumn{2}{|c|}{ Overweight (\%) } & $P$ \\
\hline \multicolumn{8}{|l|}{ Child's age group } \\
\hline 24-36 months & & & & & 20 & & 0.253 \\
\hline $37-48$ months & & & & & 41 & & \\
\hline 49-60 months & & & & & 39 & & \\
\hline \multicolumn{8}{|l|}{ Sex } \\
\hline Boys & & & & & 52 & & $0 \cdot 115$ \\
\hline Girls & & & & & 48 & & \\
\hline \multicolumn{8}{|l|}{ Birth weight for gestational age } \\
\hline Appropriate for gestational age & & & & & 86 & & 0.032 \\
\hline Small for gestational age & & & & & 5 & & \\
\hline Large for gestational age & & & & & 9 & & \\
\hline \multicolumn{8}{|l|}{ Gestational age (weeks) } \\
\hline$<37$ & & & & & 7 & & $0 \cdot 134$ \\
\hline$\geq 37$ & & & & & 93 & & \\
\hline \multicolumn{8}{|l|}{ Child's time spent in LVPA } \\
\hline$<3 \mathrm{~h} /$ week & & & & & 88 & & $0 \cdot 157$ \\
\hline$\geq 3 \mathrm{~h} /$ week & & & & & 12 & & \\
\hline \multicolumn{8}{|l|}{ Mother's BMI status } \\
\hline Normal weight & & & & & 66 & & $0 \cdot 010$ \\
\hline Overweight & & & & & 23 & & \\
\hline Obese & & & & & 11 & & \\
\hline \multicolumn{8}{|l|}{ Mother's education status } \\
\hline$<9$ years & & & & & 12 & & $0 \cdot 143$ \\
\hline $9-12$ years & & & & & 34 & & \\
\hline \multirow[t]{2}{*}{$>12$ years } & & & & & 54 & & \\
\hline & Mean & SD & Mean & SD & Mean & SD & \\
\hline Mother's age (years) & $33 \cdot 7$ & $4 \cdot 6$ & $33 \cdot 7$ & $4 \cdot 6$ & $33 \cdot 7$ & $4 \cdot 6$ & 0.948 \\
\hline
\end{tabular}

LVPA, light to vigorous physical activity. 
Table 2 Mothers' perceptions of their child's weight status by child's measured weight status: the GENESIS study

\begin{tabular}{|c|c|c|c|c|c|}
\hline \multirow[b]{2}{*}{ Mother's perception } & \multicolumn{5}{|c|}{ Measured weight status of child } \\
\hline & Underweight (\%) & Normal weight (\%) & At risk of being overweight (\%) & Overweight (\%) & Total (\%) \\
\hline \multicolumn{6}{|l|}{ I feel my child's weight is... } \\
\hline Much lower than normal & $2 \cdot 2$ & $0 \cdot 6$ & $0 \cdot 0$ & $0 \cdot 0$ & $0 \cdot 4$ \\
\hline Lower than normal & $39 \cdot 1$ & $16 \cdot 0$ & $2 \cdot 8$ & $0 \cdot 4$ & $11 \cdot 5$ \\
\hline Normal & $54 \cdot 4$ & $81 \cdot 8$ & $88 \cdot 0$ & $55 \cdot 4$ & $77 \cdot 6$ \\
\hline Higher than normal & $4 \cdot 4$ & $1 \cdot 5$ & $8 \cdot 8$ & $36 \cdot 4$ & $9 \cdot 0$ \\
\hline Much higher than normal & $0 \cdot 0$ & $0 \cdot 1$ & $0 \cdot 4$ & $7 \cdot 8$ & $1 \cdot 5$ \\
\hline
\end{tabular}

characteristics, almost $72 \%$ were normal weight, $20 \%$ were overweight and $8 \%$ were found to be obese. Moreover, the majority of mothers had a high educational level $(57 \%)$, while only $10 \%$ had less than 9 years of education.

\section{Maternal perceptions of child weight}

Table 2 illustrates the mothers' perceptions of their children's weight status by measured weight status. The majority of children $(77 \cdot 6 \%)$ were considered to have 'normal' weight. Moreover, it was found that the vast majority of 'at risk of being overweight' children (88\%) and $55 \%$ of 'overweight' children were considered to have 'normal' weight $(P<0 \cdot 001)$. The same association was observed between mothers' perceptions and the actual children's weight status in both genders (data not shown).

Overall, $38 \cdot 6 \%$ of mothers classified incorrectly their child's weight; more particularly, $37 \cdot 7 \%$ of mothers underestimated and $0.9 \%$ overestimated their child's weight. Since the percentage of overestimation was too low, we excluded these children from further analyses. The frequency of underestimation was much higher among 'at risk of being overweight' (88.3\%) and 'overweight' children $(54.5 \%)$ compared with 'underweight or normal weight' children $(18.0 \%, P<0.001)$. The percentage of correct classification was lower for boys 'at risk of being overweight' (7·6\%) or 'overweight' (33.3\%) compared with girls in these same weight status categories $(15.0 \%$ v. 59.0\%, $P=0.044$ and $P<0.001$, respectively), while no significant difference was observed in normal/underweight children $(P=0 \cdot 435)$.

Regarding child's age, it was found that misperception rate increased with increasing age. In particular, the misclassification rate was $34 \%, 38 \%$ and $42 \%$ for children aged $24-36,36-48$ and 48-60 months ( $P$ for trend $=0 \cdot 03$ ). Finally, mothers with low educational level $(<9$ years) were more likely to misclassify their child $(47 \cdot 2 \%)$ than those having moderate ( $9-12$ years) or high ( $>12$ years) educational level $(35 \cdot 9 \%$ and $35 \cdot 3 \%$, respectively, $P=0 \cdot 014)$.

\section{Factors independently associated witb maternal underestimation}

Univariate logistic regression analysis revealed that the likelihood of mothers' underestimation of their child's weight was significantly lower in girls, in children engaging in physical activity for $\geq 3 \mathrm{~h} /$ week and in children whose mothers had moderate or high educational status, compared with their counterparts. Moreover, univariate analysis demonstrated that the likelihood for mothers' misperception was higher among children aged 36-48 and 48-60 months than among those aged 24-36 months. Finally, it was found that the higher the BMI-for-age $Z$-score, the greater the odds that the mother would underestimate her child's weight status (Table 3). After performing multiple logistic regression modelling including all the aforementioned factors as well as mother's BMI status and age, it was found that the child's characteristics such as gender, BMI-for-age $Z$-score and physical activity, as well as the mother's educational level, remained statistically significant factors for the likelihood of maternal underestimation (Table 3).

Stratified analysis by child's measured weight status revealed that factors significantly associated with mothers' misperception of their 'overweight' or 'at risk of being overweight' child were child's sex, physical activity and BMI-for age Z-score. More particularly, as children's BMIfor-age $Z$-score increased, the likelihood for mothers to misclassify an overweight child decreased. Among normalweight children, the likelihood of mothers' underestimation was inversely correlated with mothers' education status and BMI-for-age Z-score (data not presented).

\section{Discussion}

In the present study, more than one-third of mothers (almost 38\%) underestimated their child's weight status. This percentage of maternal underestimation was higher among 'at risk for being overweight' or 'overweight' children, while only $16 \%$ of normal-weight children were underestimated. These findings are in agreement with percentages reported in other studies ${ }^{(23,25,26,28)}$. In particular, in a sample of mothers recruited at primary care and WIC (Special Supplemental Nutrition Program for Women, Infants, and Children) sites, $79 \%$ of mothers failed to perceive their overweight child as overweight $^{(23)}$. Similar findings were reported in a sample of 3 - to 5-year-old children in the $\mathrm{UK}^{(28)}$. Moreover, Etelson et $a l^{(26)}$ conducted a study among children aged 4 to 8 years and found that only $10 \cdot 5 \%$ of overweight children's 
Table 3 Crude and adjusted odds ratios and $95 \%$ confidence intervals for predictors of mothers' underestimation of their child's weight status among pre-school children: the GENESIS study

\begin{tabular}{|c|c|c|c|c|}
\hline & \multicolumn{2}{|c|}{ Crude } & \multicolumn{2}{|c|}{ Adjusted } \\
\hline & OR & $95 \% \mathrm{Cl}$ & OR & $95 \% \mathrm{Cl}$ \\
\hline \multicolumn{5}{|l|}{ Gender } \\
\hline Boys & Reference & & Reference & \\
\hline Girls & $0 \cdot 82^{*}$ & $0.66,1.00$ & $0 \cdot 72^{*}$ & $0.57,0.90$ \\
\hline \multicolumn{5}{|l|}{ Age group } \\
\hline $24-36$ months & Reference & & Reference & \\
\hline 36-48 months & $1 \cdot 19^{*}$ & $0.89,1.57$ & $1 \cdot 19$ & $0 \cdot 89,1 \cdot 61$ \\
\hline $48-60$ months & $1 \cdot 39^{*}$ & $1 \cdot 03,1 \cdot 87$ & $1 \cdot 30$ & $0.95,1.79$ \\
\hline \multicolumn{5}{|l|}{ Child's time spent in LVPA } \\
\hline$<3 \mathrm{~h} /$ week & Reference & & Reference & \\
\hline$\geq 3 \mathrm{~h} /$ week & $0 \cdot 73^{*}$ & $0.54,0.98$ & $0 \cdot 76^{\star}$ & $0.55,1.00$ \\
\hline Child's BMI-for-age Z-score & $1 \cdot 55^{\star}$ & $1 \cdot 40,1 \cdot 71$ & $1 \cdot 49^{*}$ & $1 \cdot 34,1 \cdot 66$ \\
\hline \multicolumn{5}{|l|}{ Mother's BMI status } \\
\hline Normal weight & Reference & & Reference & \\
\hline Overweight & $1 \cdot 09$ & $0.83,1.44$ & 0.98 & $0 \cdot 73,1 \cdot 31$ \\
\hline Obese & 0.95 & $0.63,1.43$ & $0 \cdot 78$ & $0 \cdot 50,1 \cdot 22$ \\
\hline \multicolumn{5}{|l|}{ Mother's age } \\
\hline$<35$ years & Reference & & Reference & \\
\hline$\geq 35$ years & $1 \cdot 22$ & $0.94,1.58$ & $1 \cdot 02$ & $0 \cdot 81,1 \cdot 31$ \\
\hline \multicolumn{5}{|l|}{ Mother's education status } \\
\hline$<9$ years & Reference & & Reference & \\
\hline $9-12$ years & $0.62^{*}$ & $0.42,0.89$ & $0 \cdot 70^{*}$ & $0.47,1 \cdot 00$ \\
\hline$>12$ years & $0 \cdot 60^{*}$ & $0.42,0.85$ & $0 \cdot 68^{*}$ & $0.47,0.99$ \\
\hline
\end{tabular}

LVPA, light to vigorous physical activity.

${ }^{*}$ Odds ratio was statistically significant $(P<0.05)$.

parents perceived their child's weight accurately. On the other hand, in a sample of 5500 children aged 2-11 years from the Third National Health and Nutrition Examination Survey, nearly one-third $(32 \cdot 1 \%)$ of mothers reported their overweight child as having 'absolutely the right weight' ${ }^{(16)}$. The differences observed may be attributed to different sampling methods, different definitions of excessive weight or the age range of children studied ${ }^{(16)}$. However, the fact that most mothers misclassify their overweight child as having normal weight may reflect mothers' unwillingness to admit an overweight problem for their child or even lack of awareness of what overweight means ${ }^{(16)}$.

The present study showed that normal-weight and underweight children were less likely to be misclassified. However, performing separate analyses for normal/ underweight and at risk of being overweight/overweight children, it was found that as children's BMI-for-age $Z$-score increased, mothers were less likely to misclassify their child's weight. This was an expected finding since children with BMI just above the normal-to-overweight threshold are more likely to be misclassified as normalweight than are children with substantially higher BMI ${ }^{(16)}$.

Moreover, in accordance with Baughcum et al. ${ }^{(23)}$ the current findings revealed that mothers with lower educational level were more likely to misclassify their children's weight status. Mother's high educational level may imply a better knowledge of the definition of normal/healthy and abnormal weight status of children. Moreover, higheducated mothers are more likely to be aware of the physical, social and emotional consequences of obesity, in both very young children and adults. At this point, it should be mentioned that only $10 \%$ of mothers in our cohort had a low educational status and this could affect our results. However, as has already been mentioned above, the current sample was representative for parental educational status.

The results of the current work also support the notion that parents are more likely to underestimate the weight status of boys than girls ${ }^{(16,27,34,35)}$. While this may relate to sex differences in body composition, it seems more likely to reflect social values. Mothers may be more sensitive to weight and body image issues for girls, while larger boys may be seen as having a physical advantage.

Finally, it was revealed that mothers whose children were more physically active were less likely to underestimate their child's weight status. Mothers who encourage their children to be physically active are more likely to be concerned about childhood obesity consequences and to have increased ability to distinguish abnormal from normal weight status. In addition, trainers' comments about child's body image may help mothers to recognize when their children become overweight.

However, there are some potential limitations in the current study. First, only $8 \%$ of mothers were found to be obese. This could be attributed to deliberate underreporting, which is a common weakness of using selfreported body weight. On the other hand, self-reports and measurements of body weight are highly correlated $(r=0 \cdot 86-0 \cdot 99)$, varying on average by only $1 \cdot 1$ to 
$2 \cdot 4 \mathrm{~kg}^{(36,37)}$. In addition, self-reported weights provide reasonable estimates of BMI category since the reporting error $(1-2 \mathrm{~kg})$ is a small percentage of total body weight and age-related changes in height are not a factor for prenatal populations ${ }^{(22)}$. Moreover, a valid questionnaire was used to assess the children's physical activity, although it is a well-known fact that the use of accelerometry would provide more valid data. However, the use of valid questionnaires is a common method, in particular in large epidemiological studies.

\section{Conclusions}

The current study demonstrated that more than one-third of mothers misclassify their children as being of lower weight status than their measured weight status. The misperception rate was much higher among 'at risk of being overweight' and 'overweight' children. Moreover, it was revealed that mothers are more likely to misclassify the weight status of boys and inactive children. These findings have important public health implications, given that mother's weight perception might be an important determinant of child's body weight development ${ }^{(24)}$. The attempts to combat childhood obesity might be successful if mothers recognize their 'at risk of being overweight' children. However, many parents, especially those with low educational level, may not be able to identify their overweight and 'at risk of being overweight' children as overweight or having increased weight. Therefore, paediatricians and other health-care professionals should focus primarily on these subgroups to assist mothers to correctly evaluate their children's weight status, thus helping in the early prevention of overweight and obesity.

\section{Acknowledgements}

The authors would like to thank Evdokia Oikonomou, Vivian Detopoulou, Anastasia Anastasiadou, Christine Kortsalioudaki, Elina Ioannou, Margarita Bartsota, Thodoris Liarigkovinos, Manolis Birbilis, Elina Dimitropoulou, Nikoleta Vidra, Theodoros Athanasoulis, Pari Christofidou, Lilia Charila, Sofia Tzitzirika and Christos Vassilopoulos for their contribution to the completion of the study. Y.M. was responsible for the study design and supervision of the field study. G.K. carried out the data collection and performed the statistical analyses. E.G. contributed to data collection, data management and database preparation. K.K. and E.V. carried out the data collection. All authors contributed to interpretation of the data, writing of the manuscript, reviewed the manuscript content and approved the final version submitted for publication. The GENESIS study was supported with a Research Grant from Friesland Foods Hellas. Y.M. works as a part-time scientific consultant for Friesland Foods Hellas. None of the other authors had any personal or financial conflict of interest. The study sponsor had no interference in the study design, data collection or writing of the manuscript.

\section{References}

1. Caprio S \& Genel M (2005) Confronting the epidemic of childhood obesity. Pediatrics 115, 494-495.

2. Hedley AA, Ogden CL, Johnson CL, Carroll MD, Curtin LR \& Flegal KM (2004) Prevalence of overweight and obesity among US children, adolescents, and adults, 1999-2002. JAMA 291, 2847-2850.

3. Manios Y, Magkos F, Christakis G \& Kafatos AG (2005) Twenty-year dynamics in adiposity and blood lipids of Greek children: regional differences in Crete persist. Acta Paediatr 94, 859-865.

4. Lobstein T \& Jackson-Leach R (2006) Estimated burden of paediatric obesity and co-morbidities in Europe. Part 2. Numbers of children with indicators of obesity-related disease. Int J Pediatr Obes 1, 33-41.

5. Tzotzas T \& Krassas GE (2004) Prevalence and trends of obesity in children and adults of South Europe. Pediatr Endocrinol Rev 1, Suppl. 3, 448-454.

6. Power C, Lake JK \& Cole TJ (1997) Measurement and longterm health risks of child and adolescent fatness. Int J Obes Relat Metab Disord 21, 507-526.

7. Serdula MK, Ivery D, Coates RJ, Freedman DS, Williamson DF \& Byers T (1993) Do obese children become obese adults? A review of the literature. Prev Med 22, 167-177.

8. Gortmaker SL, Must A, Perrin JM, Sobol AM \& Dietz WH (1993) Social and economic consequences of overweight in adolescence and young adulthood. $N$ Engl J Med 329, 1008-1012.

9. Must A \& Strauss RS (1999) Risks and consequences of childhood and adolescent obesity. Int J Obes Relat Metab Disord 23, Suppl. 2, S2-S11.

10. Dietz WH (1998) Health consequences of obesity in youth: childhood predictors of adult disease. Pediatrics 101, 518-525.

11. Sinha R, Fisch G, Teague B et al. (2002) Prevalence of impaired glucose tolerance among children and adolescents with marked obesity. $N$ Engl J Med 346, 802-810.

12. Sorof J \& Daniels S (2002) Obesity hypertension in children: a problem of epidemic proportions. Hypertension 40, 441-447.

13. van Putte-Katier N, Rooman RP, Haas L, Verhulst SL, Desager KN, Ramet J \& Suys BE (2008) Early cardiac abnormalities in obese children: importance of obesity per se versus associated cardiovascular risk factors. Pediatr Res 64, 205-209.

14. Mallory GB Jr, Fiser DH \& Jackson R (1989) Sleepassociated breathing disorders in morbidly obese children and adolescents. J Pediatr 115, 892-897.

15. Schwimmer JB, Burwinkle TM \& Varni JW (2003) Healthrelated quality of life of severely obese children and adolescents. JAMA 289, 1813-1819.

16. Maynard LM, Galuska DA, Blanck HM \& Serdula MK (2003) Mothers' perceptions of weight status of children. Pediatrics 111, 1226-1231.

17. Birch LL \& Fisher JO (1998) Development of eating behaviors among children and adolescents. Pediatrics 101, 539-549.

18. Satter EM (1996) Internal regulation and the evolution of normal growth as the basis for prevention of obesity in children. J Am Diet Assoc 96, 860-864.

19. Moore LL, Lombardi DA, White MJ, Campbell JL, Oliveria SA \& Ellison RC (1991) Influence of parents' physical activity levels on activity levels of young children. J Pediatr 118, 215-219. 
20. Sallis JF, Simons-Morton BG, Stone EJ et al. (1992) Determinants of physical activity and interventions in youth. Med Sci Sports Exerc 24, S248-S257.

21. Barlow SE \& Dietz WH (1998) Obesity evaluation and treatment: Expert Committee recommendations. The Mothers' and Child Health Bureau, Health Resources and Services Administration and the Department of Health and Human Services. Pediatrics 102, E29.

22. Elder JP, Ayala GX \& Harris S (1999) Theories and intervention approaches to health-behavior change in primary care. Am J Prev Med 17, 275-284.

23. Baughcum AE, Chamberlin LA, Deeks CM, Powers SW \& Whitaker RC (2000) Mothers' perceptions of overweight preschool children. Pediatrics 106, 1380-1386.

24. Kroke A, Strathmann S \& Gunther AL (2006) Mothers' perceptions of her child's body weight in infancy and early childhood and their relation to body weight status at age 7 . Eur J Pediatr 165, 875-883.

25. Eckstein KC, Mikhail LM, Ariza AJ, Thomson JS, Millard SC \& Binns HJ (2006) Parents' perceptions of their child's weight and health. Pediatrics 117, 681-690.

26. Etelson D, Brand DA, Patrick PA \& Shirali A (2003) Childhood obesity: do parents recognize this health risk? Obes Res 11, 1362-1368.

27. Jeffery AN, Voss LD, Metcalf BS, Alba S \& Wilkin TJ (2005) Parents' awareness of overweight in themselves and their children: cross sectional study within a cohort (EarlyBird 21). BMJ 330, 23-24

28. Carnell S, Edwards C, Croker H, Boniface D \& Wardle J (2005) Parental perceptions of overweight in 3-5 y olds. Int J Obes (Lond) 29, 353-355.
29. Huang JS, Becerra K, Oda T, Walker E, Xu R, Donohue M, Chen I, Curbelo V \& Breslow A (2007) Parental ability to discriminate the weight status of children: results of a survey. Pediatrics 120, e112-e119.

30. Manios Y (2006) Design and descriptive results of the 'Growth, Exercise and Nutrition Epidemiological Study In preSchoolers': the GENESIS study. BMC Public Health 6, 32.

31. National Center for Health Statistics (2000) 2000 CDC Growth Charts: United States. Hyattsville, MD: NCHS.

32. Cole TJ, Faith MS, Pietrobelli A \& Heo M (2005) What is the best measure of adiposity change in growing children: BMI, BMI \%, BMI Z-score or BMI centile? Eur J Clin Nutr 59, 419-425.

33. National Institutes of Health (1998) Clinical Guidelines on the Identification, Evaluation, and Treatment of Overweight and Obesity in Adults - The Evidence Report. Obes Res 6, Suppl. 2, 51S-209S.

34. Fisher L, Fraser J \& Alexander C (2006) Caregivers' inability to identify childhood adiposity: a cross-sectional survey of rural children and their caregivers' attitudes. Aust J Rural Health 14, 56-61.

35. Campbell MW, Williams J, Hampton A \& Wake M (2006) Mothers' concern and perceptions of overweight in Australian preschool-aged children. Med J Aust 184, $274-277$

36. Stevens-Simon C, Roghmann KJ \& McAnarney ER (1992) Relationship of self-reported prepregnant weight and weight gain during pregnancy to mothers' body habitus and age. J Am Diet Assoc 92, 85-87.

37. Stewart AL (1982) The reliability and validity of selfreported weight and height. J Chronic Dis 35, 295-309. 